\title{
The effect of grain size on storage and distribution of defects at plastic deformation of polycrystalline FCC alloys based on copper
}

\author{
N. A. Koneva*, E. V. Kozlov, L. I. Trishkina \\ Tomsk State University of Architecture and Building, Solyanaya Sq. 2, Tomsk 634003, Russia
}

Received 29 January 2015, received in revised form 21 May 2015, accepted 21 May 2015

\begin{abstract}
The defect structure forming during deformation of the fcc polycrystalline solid solution $\mathrm{Cu}-\mathrm{Al}$ and $\mathrm{Cu}-\mathrm{Mn}$ with different grain sizes $(10-240 \mu \mathrm{m})$ was studied by TEM. Plastic deformation of the alloy samples was carried out in tension at rate of $2 \times 10^{-2} \mathrm{sec}^{-1}$ at the temperatures of $293-573 \mathrm{~K}$. The scalar dislocation density and its components (the density of geometrically necessary dislocations and the density of statistically stored dislocations), the size of dislocation cells and the curvature-torsion crystalline lattice were measured. Both the average parameters of all the samples and the local ones were determined at various distances from the grain boundaries.

The study showed the presence of a hardened zone near the grain boundaries, the size of which decreases with a decreasing grain size.
\end{abstract}

K e y words: alloys, polycrystal, grains, grain boundaries, deformation, defects

\section{Introduction}

Plastic deformation of a polycrystalline aggregate is a complex process [1-4]. In particular, it is caused by the contribution to work hardening of different grain sizes and the sites of the material localized near and far from the grain boundaries (GBs).

Therefore, it is important to determine the dislocation structure (DS) parameters both in the vicinity of the GBs and far from them. At the same time, it is important to follow the dependence of the parameters of the DS as a function of the grain size. These questions in scientific publications have been discussed insufficiently. The dislocation density, the dislocation cell size, the curvature-torsion of the crystal lattice, the internal stresses belong to the important parameters of the defect structure of the deformed material.

For many years the dislocation structure was usually characterized by the scalar dislocations density $(\rho)$. The development of the dislocation science has led to the division of $\rho$ into components [1] having various physical content. Multiplication of dislocations and the dislocation reactions are random processes.
The dislocations which slowed down in such way are so-called statistically stored dislocations (SSD). Statistically stored dislocations are decelerated by relatively weak barriers - other dislocations.

If there are stronger barriers (grain boundaries, twin boundaries, particles of the second phases) in the material, gradients of plastic deformation appear. If the gradients of the plastic deformation are present, in addition to the dislocations density $\rho_{\mathrm{S}}$ there is also an accumulation of the geometrically necessary dislocations (GND) with the density $\rho_{\mathrm{G}}$. In this case [3]:

$$
\rho=\rho_{\mathrm{S}}+\rho_{\mathrm{G}} .
$$

The component of the dislocation structure $\rho_{\mathrm{G}}$ was introduced first by M. F. Ashby [1] to assess the role of grain boundaries in the formation of the dislocation structure. However, a detailed analysis of the $\rho_{\mathrm{S}}$ and $\rho_{\mathrm{G}}$ contributions to the total scalar dislocation density has been absent so far.

The aim of this work is to study the influence of the grain size on the scalar dislocation density, its components and other parameters of DS and their vari-

*Corresponding author: e-mail address: koneva@tsuab.ru 
ation depending on the distance from the GB.

\section{Materials and methods}

The objects of study are the polycrystalline FCC solid solutions of $\mathrm{Cu}-\mathrm{Al}$ and $\mathrm{Cu}-\mathrm{Mn}$. The alloys of $\mathrm{Cu}-\mathrm{Al}$ were studied in the concentration range of $\mathrm{Al}$ $0.5-14$ at.\%, the alloys of $\mathrm{Cu}-\mathrm{Mn}$ - in the concentration range of Mn $0.4-25$ at.\%. Plastic deformation was carried out in tension at a rate of $2 \times 10^{-2} \mathrm{sec}^{-1}$ at temperatures of $293-573 \mathrm{~K}$. The dislocation structure of samples deformed to various degree of deformation was studied on the foils by TEM. Measurement of the following parameters of the defect structure was made: the scalar dislocation density $(\rho)$, the density of the geometrically necessary dislocations $\left(\rho_{\mathrm{G}}\right)$, the density of the statistically stored dislocations $\left(\rho_{\mathrm{S}}\right)$, the curvature-torsion of the crystal lattice $(\chi)$ and some other parameters. Both the average parameters of defect structure, and the local ones at various distances from the GB were defined. The scalar dislocation density and the size of dislocation cells were measured by the well-known cross-section method [5]. The GND density is given by [3]:

$$
\rho_{\mathrm{G}}=(R b)^{-1},
$$

where $R$ is the bending radius of the crystalline lattice, $b$ is Burgers vector. In [6] it is shown that

$$
\rho_{\mathrm{G}}=(R b)^{-1}=\frac{\chi}{b},
$$

where $\chi=\frac{\partial \varphi}{\partial l}$ is the curvature-torsion of the crystal lattice $(\varphi$ is the angle of inclination of the crystal plane, $l$ is the distance on the plane). The value $\frac{\partial \varphi}{\partial l}$ can be determined using the bending extinction contours observed in the TEM images of deformed material [6]. This method was used in this study to determine $\rho_{\mathrm{G}}$. After determining the densities of $\rho$ and $\rho_{\mathrm{G}}$ statistically stored dislocations $\rho_{\mathrm{S}}$ were determined using Eq. (1).

\section{Results and discussion}

As it is obvious from Fig. 1, the scalar dislocation density decreases with increasing average grain size. The dependence of the dislocations density on the grain size was described by, H. Conrad [7] and A. N. Orlov $[8]$ as follows:

$$
\rho=k \varepsilon d^{-1},
$$

where $k$ is a constant, $\varepsilon$ is the degree of deformation,

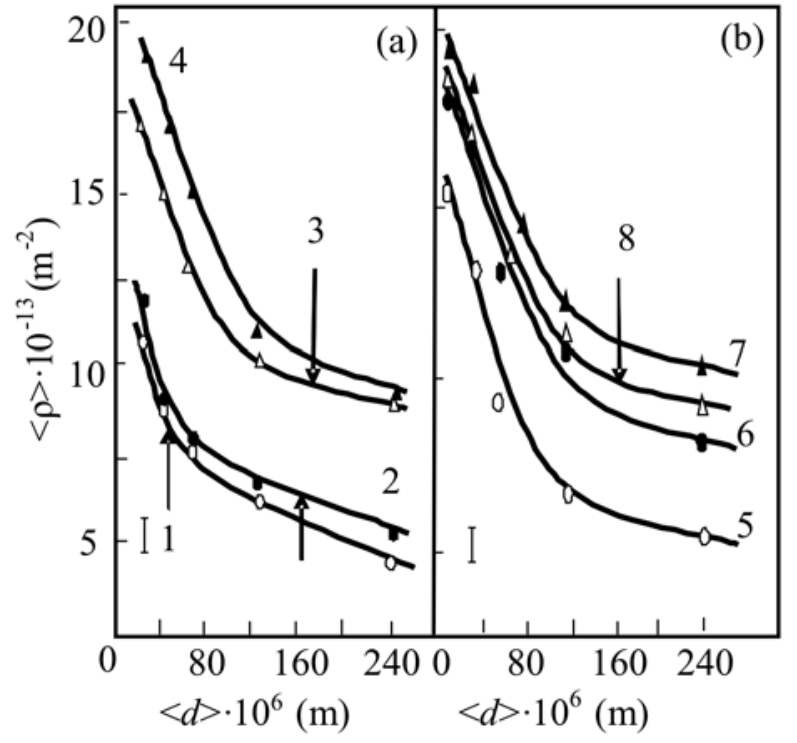

Fig. 1. The dependence of the average scalar dislocation density $\langle\rho\rangle$ as a function of the average grain size $\langle d\rangle$ in the alloys $\mathrm{Cu}-\mathrm{Al}$ and $\mathrm{Cu}-\mathrm{Mn}: 1-\mathrm{Cu}+0.5$ at.\%Al; $2-$ $\mathrm{Cu}+5$ at. $\% \mathrm{Al} ; 3-\mathrm{Cu}+10 \mathrm{at} . \% \mathrm{Al} ; 4-\mathrm{Cu}+14$ at. $\% \mathrm{Al} ; 5-$ $\mathrm{Cu}+0.4$ at. $\% \mathrm{Mn} ; 6-\mathrm{Cu}+6$ at. $\% \mathrm{Mn} ; 7-\mathrm{Cu}+13 \mathrm{at} . \% \mathrm{Mn} ; 8$ - $\mathrm{Cu}+19$ at.\%Mn deformed at $T_{\text {def }}=293 \mathrm{~K}$ up to $\varepsilon_{\text {true }}=$ 0.20 .

$d$ is the grain size. Therefore, it is interesting to plot dependences $\rho=f(d)$ and $\rho=f\left(d^{-1}\right)$ as it can be seen in Figs. 1 and 2. It is obvious that the dependences $\rho$ $=f(d)$ and $\rho=f\left(d^{-1}\right)$ are not linear. At the grain size $d \approx 100 \mu \mathrm{m}$ the slope of the dependence significantly changes. Thus the grain size $d \approx 100 \mu \mathrm{m}$ seems to be critical for the accumulation of the dislocations during deformation. Above this value the dislocation density exhibits only a weak dependence on the grain size.

This result suggests that above $100 \mu \mathrm{m}$ the accumulation of the dislocations is generally governed by processes occurring in the grain interiors, whereas the role of GB is not so significant.

The two straight segments can be observed also in $\rho=f\left(d^{-1}\right)$ plot (Fig. 2). The physical and mathematical picture of the phenomenon is quite complex. In order to elucidate the observed phenomenon, the strengthened boundary zones (SBZ) should be investigated in detail [9].

The SBZ can be determined from measurement of dislocation density as a function of the distance from the GB, as it is presented in Fig. 3 for the alloys $\mathrm{Cu}+0.5$ at. $\% \mathrm{Al}$ and $\mathrm{Cu}+14$ at.\% $\mathrm{Al}$ having grain size $\langle d\rangle=60 \mu \mathrm{m}$. We can see that the width of the zone near the grain boundaries with a high dislocation density is $2 \mu \mathrm{m}$ in this case. The dependence of the width of the hardened zone on the grain size and the degree of deformation for the different alloys $\mathrm{Cu}-\mathrm{Al}$ can be seen in Fig. 4. It is obvious that 


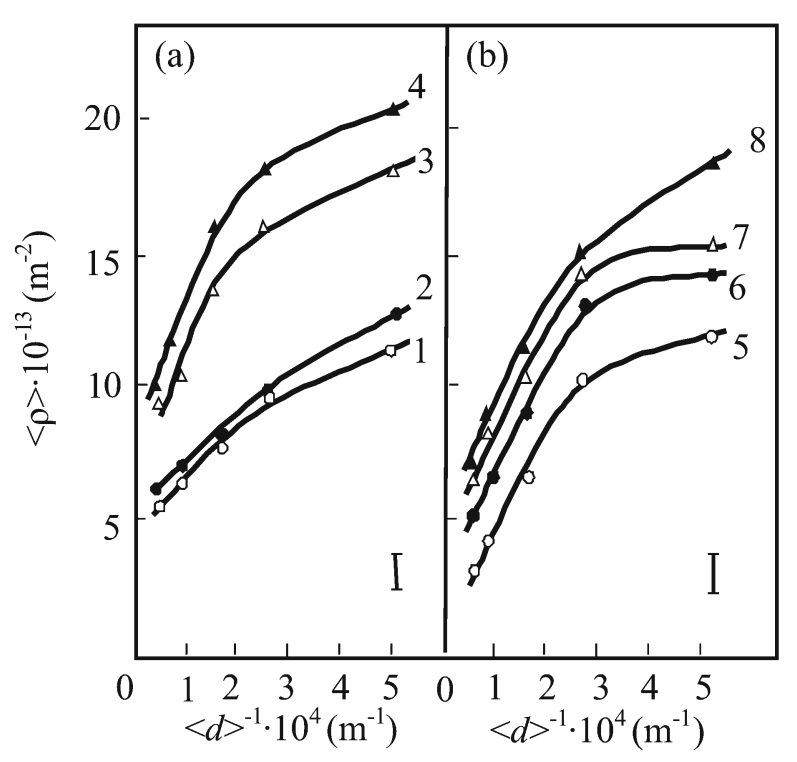

Fig. 2. The dependence of the average scalar dislocation density $\langle\rho\rangle$ as the function of the inverse average grain size $\left\langle d^{-1}\right\rangle$ in the alloys $\mathrm{Cu}-\mathrm{Al}$ and $\mathrm{Cu}-\mathrm{Mn}$ : $1-\mathrm{Cu}+0.5$ at. $\% \mathrm{Al} ; 2-\mathrm{Cu}+5$ at. $\% \mathrm{Al} ; 3-\mathrm{Cu}+10 \mathrm{at} . \% \mathrm{Al}$; 4 - Cu14at.\%Al; 5 - Cu+0.4at.\%Mn; 6 - Cu+6at.\%Mn; 7 $-\mathrm{Cu}+13 \mathrm{at} . \% \mathrm{Mn} ; 8-\mathrm{Cu}+19 \mathrm{at} . \% \mathrm{Mn}, \varepsilon_{\text {true }}=0.20, T_{\text {def }}=$ $293 \mathrm{~K}$.

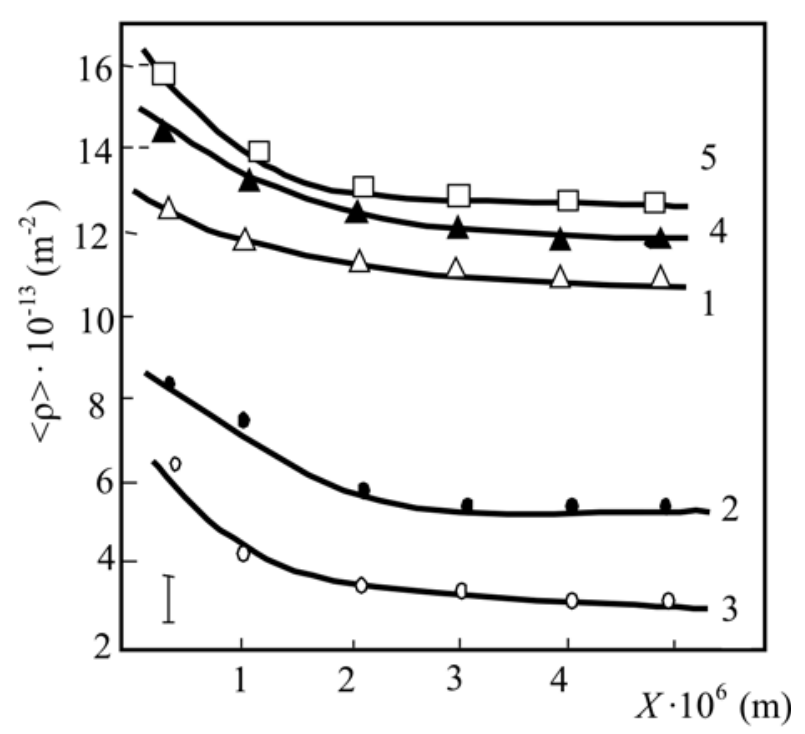

Fig. 3. Change of the average scalar dislocation density $\langle\rho\rangle$ with the distance from the grain boundaries at $\varepsilon_{\text {true }}$ $=0.20$ for two alloys deformed at different temperatures, 1, 2, $3-\mathrm{Cu}+0.5$ at.\%Al; 4, $5-\mathrm{Cu}+14$ at.\%Al. $1-\mathrm{T}=$ $293 \mathrm{~K} ; 2-T=523 \mathrm{~K} ; 3-T=573 \mathrm{~K} ; 4-T=473 \mathrm{~K} ; 5-$ $T=673 \mathrm{~K}$. The grain size $\langle d\rangle=60 \mu \mathrm{m}$.

the width of the SBZ increases with decreasing grain size.

It should be noted that although the SBZs are

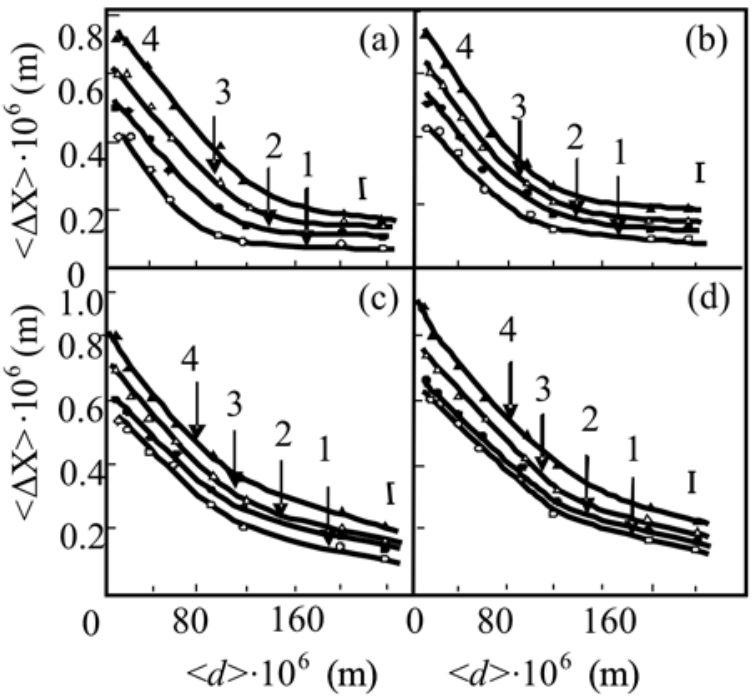

Fig. 4. The dependences of the size $(\Delta X)$ of areas with a high density of dislocations $(\langle\rho\rangle)$ near the grain boundary on the grain size $(\langle d\rangle)$ at different degrees of deformation $\left(\varepsilon_{\text {true }}\right): 1-0.50 ; 2-0.25 ; 3-0.45 ; 4-0.60$. Alloys: (a) $\mathrm{Cu}+0.5 \mathrm{at} . \% \mathrm{Al} ;$ (b) $\mathrm{Cu}+5 \mathrm{at} . \% \mathrm{Al} ;$ (c) $\mathrm{Cu}+10 \mathrm{at} . \% \mathrm{Al}$; (d) $\mathrm{Cu}+14 \mathrm{at} . \% \mathrm{Al} . T_{\text {def }}=293 \mathrm{~K}$.

rather narrow, they can make a significant contribution to hardening of a polycrystal.

As indicated above, the scalar dislocation density can be represented by the sum of the components $\rho_{\mathrm{G}}$ and $\rho_{\mathrm{S}}$, see Eq. (1). In this paper, these components of the scalar dislocation density were measured using TEM (see Section 2). As a result, it was found that in a wide range of the grain sizes $(10-240 \mu \mathrm{m})$ the $\rho_{\mathrm{G}}$ component is smaller than the $\rho_{\mathrm{S}}$ component. However, for $<d>=10$ and $20 \mu \mathrm{m} \rho_{\mathrm{G}}$ is greater than or comparable with $\rho_{\mathrm{S}}$ in the vicinity of GB as it is presented in Fig. 5 for alloy $\mathrm{Cu}+5$ at.\%Al. It is obvious that at $\langle d\rangle=20 \mu \mathrm{m}$ near the GB up to $\varepsilon_{\text {true }} \approx 0.15 \rho_{\mathrm{G}}>$ $\rho_{\mathrm{S}}$. Further increase of the induced deformation leads to the relation $\rho_{\mathrm{S}}>\rho_{\mathrm{G}}$. These results are in agreement with the earlier data obtained by the authors on other materials $[6,10]$ which shows the existence of the critical grain $d_{\mathrm{cr}} \approx 10 \mu \mathrm{m}$ at which $\rho_{\mathrm{S}}$ becomes equal to $\rho_{\mathrm{G}}$ and at a further decrease in the grain size $\rho_{\mathrm{G}}$ exceeds $\rho_{\mathrm{S}}$. For ultrafine-grained materials it was established [10] that $\rho_{\mathrm{G}} \gg \rho_{\mathrm{S}}$, and for nanomaterials $\rho_{\mathrm{S}} \approx 0$. The plastic deformation is influenced by accumulation of the GND which are caused by partial disclinations in the GB and in the joints of the grains [11-13].

The characteristics of various dislocation substructures were measured in this work along with the dislocation density. A special attention was paid to the dislocation cellular substructure. Figure 6 shows the TEM image of the cellular dislocation substructure near the GBs in the $\mathrm{Cu}+6 \mathrm{at} . \% \mathrm{Mn}$ alloy deformed 


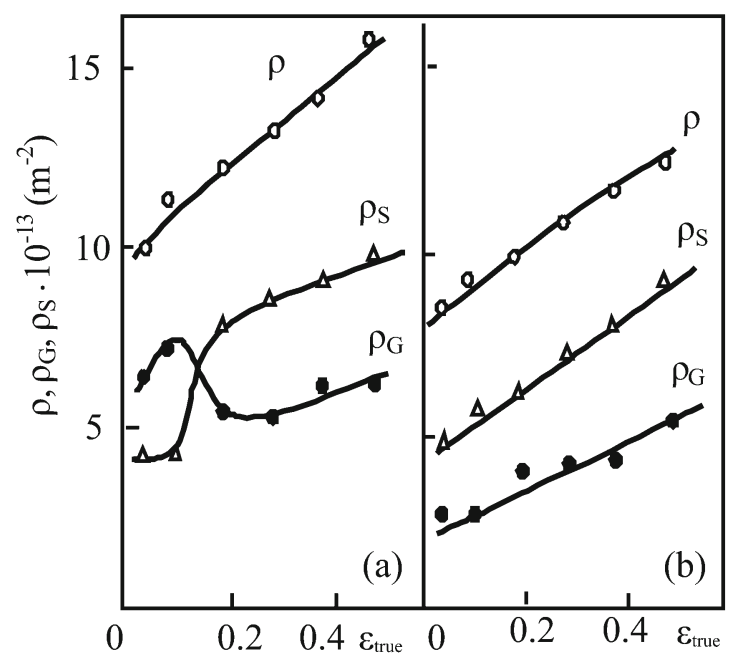

Fig. 5. The dependence of the average scalar dislocation density $\langle\rho\rangle$ and its components $\rho_{\mathrm{S}}$ and $\rho_{\mathrm{G}}$ near and far from the GBs on the degree of the deformation $\varepsilon_{\text {true }}$ : (a) near the grain boundary, (b) away from the grain boundary. Alloy $\mathrm{Cu}+5$ at.\%Al. Grain size $\langle d\rangle=20 \mu \mathrm{m}$. $T_{\text {def }}=$ $293 \mathrm{~K}$.

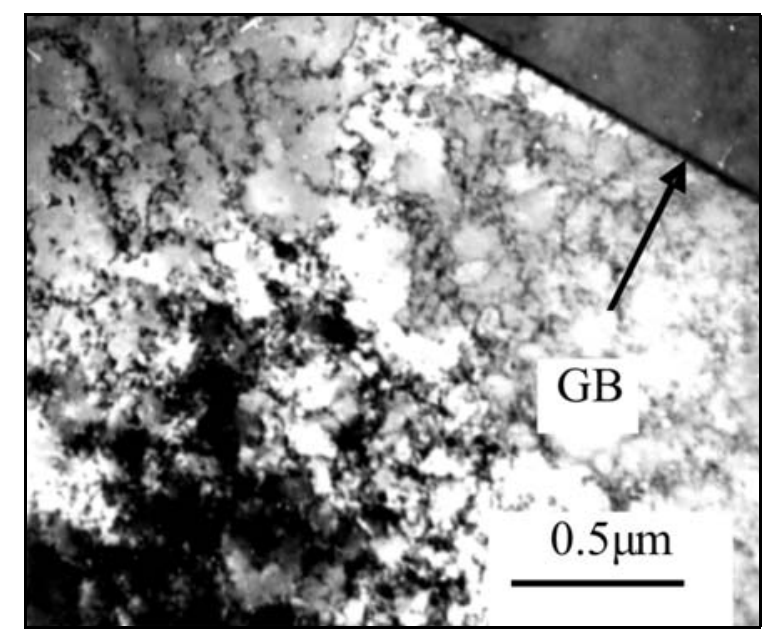

Fig. 6. Formation of a cellular dislocation substructure near the grain boundary. The grain size $d=60 \mu \mathrm{m}, \varepsilon_{\text {true }}$ $=0.20, T_{\mathrm{def}}=293 \mathrm{~K}$. GB is grain boundary.

$\left(\varepsilon_{\text {true }}=0.35\right)$ at $T=293 \mathrm{~K}$. One can see that as we approach the GBs, the cell size decreases. Similar pattern was observed also in other alloys [14]. Thus, the boundary area can give additional strengthening not only due to the high dislocation density near the GBs, but also due to the smaller size of the dislocation cells compared with the grain interior. Let us recall that the smaller dislocation cells, the greater the deformation resistance [15].

It is known $[6,11,12]$ that the plastic deformation is accompanied by the formation and development of
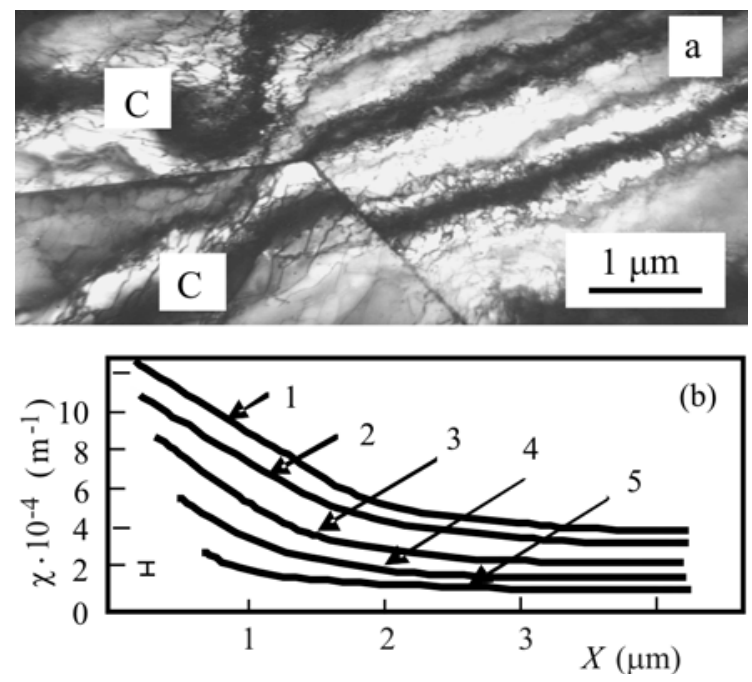

Fig. 7. TEM image of the grain joint (a) and dependences of the curvature-torsion lattice $(\chi)$ on the distance from the joints of the grain boundaries in an alloy $\mathrm{Cu}+0.5$ at.\% $\mathrm{Al}$ for different grain sizes $(<d\rangle)$. (b): $1-$ $10 \mu \mathrm{m} ; 2-40 \mu \mathrm{m} ; 3-100 \mu \mathrm{m} ; 4-200 \mu \mathrm{m} ; 5-240 \mu \mathrm{m}$.

$T_{\text {def }}=293 \mathrm{~K} . \mathrm{C}$ is a sign of the extinction contours.

the curvature-torsion $(\chi)$ of the crystal lattice that leads to arising of internal stresses. We would like to present that the curvature-torsion of the crystal lattice and, consequently, of the internal stress originate from the steps on the GBs and the GBs triple junctions. Figure 7a shows TEM images of the GBs and the GBs triple junction. The bending extinction contours $(C)$ indicate the presence of the curvature-torsion of the crystal lattice in the image. The curvature-torsion of the crystal lattice forms partial disclinations located on the GBs and the grain junctions [11-13]. The results of the measurement $\chi$ are given in Fig. $7 \mathrm{~b}$ as the function of the distances from the grain joints for an alloy $\mathrm{Cu}+5$ at.\% $\mathrm{Al}$ for different degrees of deformation. The distinction $\chi$ near and far from the GBs and an increase in this distinction are clearly seen at increasing degrees of deformation. The decrease in the grain size is accompanied by a relative increase in the width of the zone near the grain boundaries with a high value of $\chi$ compared with the grain body.

Thus, the results indicate that there is an area near grain boundaries (zone) with a higher curvature-torsion of the crystalline lattice, and, hence, higher internal stresses compared with the grain interior. A similar result was obtained by the authors [16] during the study of the distribution of the internal stresses in the UFG copper and nickel.

\section{Conclusion}

In this work the presence of a hardened zone 
near the grain boundaries was shown for $\mathrm{Cu}-\mathrm{Al}$ and $\mathrm{Cu}-\mathrm{Mn}$ alloys having different grain size. In this zone, both the scalar dislocation density and the curvature-torsion of the crystal was found higher, whereas the dislocation cell size was smaller in comparison with the grain interior. Further, the relationship between the parameters $\rho_{\mathrm{S}}$ and $\rho_{\mathrm{G}}$ can change. The existence of the hardened zone near the grain boundaries must be taken into account when the hardening mechanisms of a polycrystalline aggregate are considered.

\section{Acknowledgements}

This paper is dedicated to Prof. Pavel Lukáč on the occasion of his 80th birthday.

The authors are grateful to the Department of Physics of Materials, the Department of Mathematics and Physics of the Charles University in Prague for the invitation to prepare an article for this special edition.

This work was financially supported within the state task of the Russian Ministry No. 3.295.2014/K and with the financial support of the RFFI under the research project No. $14-02-92605$ KO_a. The authors are grateful for the financial support.

\section{References}

[1] Ashby, M. F.: Phil. Mag., 21, 1970, p. 399. doi: $10.1080 / 14786437008238426$

[2] Meyers, M. A.: Mechanical Behavior of Materials. New Jersey, Prentice Hall Inc. 1999.

[3] Courtney, T. H.: Mechanical Behavior of Materials. McGraw-Hill International Editions: Material Science/Metallurgy Series. 2nd Edition. New York, McGraw-Hill 2000.
[4] Hansen, N., Huang, X., Winter, G.: Mat. Sci. Eng. A, 494, 2008, p. 61. doi:10.1016/j.msea.2007.10.086

[5] Saltikov, S. A.: Stereometric Metallography. Moscow, Metallurgia 1970.

[6] Koneva, N. A., Kozlov, E. V., Popova, N. A., Fedorisheva, M. V.: Mat. Sci. Forum, 633-634, 2010, p. 605. doi:10.4028/www.scientific.net/MSF.633-634.605

[7] Conrad, H.: In: Ultrafine-Grain Metals. Eds.: Burke, J. J., Weiss, V. Syracuse, Syracuse University Press 1970.

[8] Orlov, A. H.: The Physics of Metals and Metallography (Fizika Metallov and Metallovedenie), 44, 1977, p. 966. (in Russian).

[9] Kozlov, E. V., Zhdanov, A. N., Koneva, N. A.: Physical Mesomechanics, 9, 2006, p. 81. (in Russian).

[10] Kozlov, E. V., Koneva, N. A., Popova, N. A.: Physical Mesomechanics, 12, 2009, p. 280. doi:10.1016/j.physme.2009.12.010

[11] Rybin, V. V.: Large Plastic Deformation and Fracture of Metals. Moscow, Metallurgia 1986.

[12] Klimanek, P., Romanov, A. E., Seefeldt, M.: Local Lattice Rotations and Disclinations in Microstructures of Distorted Crystalline Materials. Uetikon-Zuerich, Scitec Publications Ltd. 2002.

[13] Koneva, N. A., Kozlov, E. V., Popova, N. A., Zhdanov, A. N., Fedorisheva, M. V.: Mat. Sci. Forum, 584-586, 2008, p. 269. doi:10.4028/www.scientific.net/MSF.584-586.269

[14] Koneva, N. A., Trishkina, L. I., Kozlov, E. V.: Russian Physics Journal, 54, 2012, p. 867. doi:10.1007/s11182-011-9695-z

[15] Staker, M. R., Holt, D. L.: Acta Met., 20, 1972, p. 569.

[16] Koneva, N. A., Kozlov, E. V., Trishkina, L. I., Popova, N. A.: Russian Physics Journal, 57, 2014, p. 187. doi:10.1007/s11182-014-0224-8 